\title{
OTHER
}

\section{Brave New Arctic: The Untold Story of the Melting North}

By Mark C. Serreze. 2018. Princeton University Press. 264 pages, 24.95 USD, Cloth, 272 pages, 17.95 USD, Paper.

Climate change is happening at twice the rate in the Arctic compared with the global average. Air temperature is increasing and coverage by glaciers and sea ice is decreasing every year. The physical changes then have cascading impacts on the people and animals that live in the Arctic. Brave New Arctic lays out much of the evidence showing how the Arctic climate has

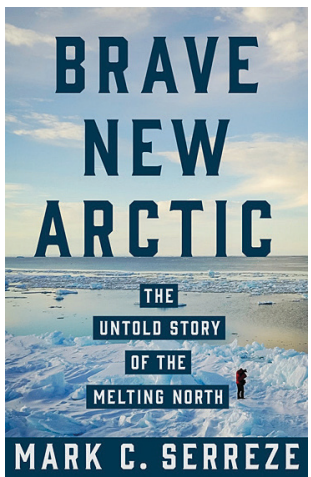
been changing over the last 50 years (and beyond), including the mechanisms behind that change. The author, Mark Serreze, has been studying Arctic climate for decades, and is a global expert on climate change in the Arctic.

A really interesting aspect of this book is that it focusses on the history of Arctic climate science. Serreze began his studies of the Arctic climate in the late 1970s, and has experienced much of this history firsthand. Earlier in the century, scientists had detected a cooling trend, and early during his career, the evidence supporting widespread climate change in the Arctic seemed weak. However, in the 1990s and onwards, particularly at the turn of the century, evidence of climate change, and in particular, humancaused climate change, began piling up. The book also delves into many of the social repercussions and politics around evidence of climate change in the Arctic.

Overall, I wholeheartedly recommend this book. It provides accessible and easily digestible information on climate change in the Arctic. The book also relies on personal anecdotes from the author, which add an interesting element to the history. Any naturalist interested in climate change should be especially interested in this book, which details climate change in the region being most impacted.

William D. Halliday

Wildlife Conservation Society Canada, Whitehorse, YT, Canada and

School of Earth and Ocean Sciences, University of Victoria, Victoria, BC, Canada

(C) The author. This work is freely available under the Creative Commons Attribution 4.0 International license (CC BY 4.0). 